\title{
Seasonal lake surface water temperature trends reflected by heterocyst glycolipid-based molecular thermometers
}

\author{
T. Bauersachs ${ }^{1}$, J. Rochelmeier ${ }^{1}$, and L. Schwark ${ }^{1,2}$ \\ ${ }^{1}$ Department of Organic Geochemistry, Institute of Geosciences, Christian-Albrechts-University, Ludewig-Meyn-Straße 10, \\ 24118 Kiel, Germany \\ ${ }^{2}$ Department of Chemistry, WA-OIGC, Curtin University, G.P.O. Box U1987, 6845 Perth, Western Australia, Australia \\ Correspondence to: T. Bauersachs (thb@gpi.uni-kiel.de)
}

Received: 7 October 2014 - Published in Biogeosciences Discuss.: 14 January 2015

Revised: 4 May 2015 - Accepted: 9 May 2015 - Published: 17 June 2015

\begin{abstract}
It has been demonstrated that the relative distribution of heterocyst glycolipids (HGs) in cultures of $\mathrm{N}_{2}$-fixing heterocystous cyanobacteria is largely controlled by growth temperature, suggesting a potential use of these components in paleoenvironmental studies. Here, we investigated the effect of environmental parameters (e.g., surface water temperatures, oxygen concentrations and $\mathrm{pH}$ ) on the distribution of HGs in a natural system using water column filtrates collected from Lake Schreventeich (Kiel, Germany) from late July to the end of October 2013. HPLC-ESI/MS (highperformance liquid chromatography coupled to electrospray ionization-mass spectrometry) analysis revealed a dominance of 1-(O-hexose)-3,25-hexacosanediols $\left(\mathrm{HG}_{26}\right.$ diols) and 1-(O-hexose)-3-keto-25-hexacosanol ( $\mathrm{HG}_{26}$ keto-ol) in the solvent-extracted water column filtrates, which were accompanied by minor abundances of 1-(O-hexose)-3,27octacosanediol $\left(\mathrm{HG}_{28}\right.$ diol) and 1-(O-hexose)-3-keto-27octacosanol ( $\mathrm{HG}_{28}$ keto-ol) as well as 1-(O-hexose)-3,25,27octacosanetriol ( $\mathrm{HG}_{28}$ triol) and 1-(O-hexose)-3-keto-25,27octacosanediol $\left(\mathrm{HG}_{28}\right.$ keto-diol). Fractional abundances of alcoholic and ketonic HGs generally showed strong linear correlations with surface water temperatures and no or only weak linear correlations with both oxygen concentrations and $\mathrm{pH}$. Changes in the distribution of the most abundant diol and keto-ol (e.g., $\mathrm{HG}_{26}$ diol and $\mathrm{HG}_{26}$ keto-ol) were quantitatively expressed as the $\mathrm{HDI}_{26}$ (heterocyst diol index of 26 carbon atoms) with values of this index ranging from 0.89 in mid-August to 0.66 in mid-October. An average $\mathrm{HDI}_{26}$ value of 0.79 , which translates into a calculated surface water temperature of $15.8 \pm 0.3^{\circ} \mathrm{C}$, was obtained from surface sediments collected from Lake Schreventeich. This temper-
\end{abstract}

ature - and temperatures obtained from other HG indices (e.g., $\mathrm{HDI}_{28}$ and $\mathrm{HTI}_{28}$ ) - is similar to the one measured during maximum cyanobacterial productivity in early to midSeptember and suggests that HGs preserved in the sediment record of Lake Schreventeich reflect summer surface water temperatures. As $\mathrm{N}_{2}$-fixing heterocystous cyanobacteria are widespread in present-day freshwater and brackish environments, we conclude that the distribution of HGs in sediments may allow for the reconstruction of surface water temperatures of modern and potentially ancient lacustrine settings.

\section{Introduction}

Lipid paleothermometers have become an indispensable tool in paleoenvironmental studies as they allow for the reconstruction of oceanic surface water temperatures over geological timescales and thus provide essential information on past climate changes. The two most commonly employed lipid paleothermometers are the $\mathrm{U}_{37}^{\mathrm{K}}$ (Brassell et al., 1986) and the TEX 86 (Schouten et al., 2002), which use the distribution of long-chain alkenones or glycerol dialkyl glycerol tetraethers (GDGTs) preserved in marine sediments to reconstruct oceanic surface water temperatures. The more recently introduced long-chain diol index (LDI), which is based on the distribution of $\mathrm{C}_{28}$ 1,13-, $\mathrm{C}_{30}$ 1,13-, and $\mathrm{C}_{30}$ 1,15-diols produced by eustigmatophyte algae (Rampen et al., 2012), provides an additional mean to determine past changes in sea surface temperatures (SSTs) and has successfully been applied in a number of paleoceanographic studies (Smith et al., 2013; Rodrigo-Gámiz et al., 2014). 
The $\mathrm{TEX}_{86}$ proxy has previously been applied to a number of freshwater environments but seems to reliably predict surface water temperatures only in some large lakes, such as the North American Great Lakes and the African Rift Valley lakes, where the contribution of isoprenoid GDGTs of a terrestrial origin is only negligible (Powers et al., 2010). Likewise, long-chain alkenones have been reported from some modern lake systems (Volkman et al., 1988; Thiel et al., 1997; Theroux et al., 2012) and were employed to reconstruct past changes in surface water temperatures in Lake Steisslingen, SW Germany (Zink et al., 2001). However, due to our incomplete knowledge on the biological sources of long-chain alkenones and their comparatively limited distribution in freshwater environments, temperature estimates based on long-chain alkenones in lacustrine sediments are comparatively few.

Another lipid paleothermometer that has attracted considerable attention over the recent past is the MBT (methylation index of branched tetraethers)/CBT (cyclization ratio of branched tetraethers) index. This proxy, based on the distribution of branched GDGTs that are ubiquitously distributed in soils, peats as well as lacustrine and coastal marine sediments (see Schouten et al., 2013, and references therein), has been shown to correlate well with mean annual air temperature (MAAT) and soil pH (Weijers et al., 2007). It has since also been applied to various lakes and coastal marine environments, containing a large proportion of terrestrial organic matter, to infer past changes in continental climate (Zink et al., 2010; Niemann et al., 2012; Berke et al., 2014). However, a number of more recent studies have demonstrated that branched GDGTs may also be produced in aquatic systems, possibly complicating the application of the MBT/CBT index as a tool for reconstructing MAAT (De Jonge et al., 2014; Weber et al., 2015). Nonetheless, the MBT/CBT index and other lipid paleothermometers have proven most valuable in determining trends in climate evolution both on regional and global scales. A lipid-based proxy that allows deciphering past changes in surface water temperatures in lacustrine environments on the contrary is currently missing (Castañeda and Schouten, 2011).

Heterocystous cyanobacteria are oxygenic photoautotrophs that are known to be an abundant component of the phytoplankton community of many present-day freshwater lakes of polar to tropical latitudes (Whitton, 2012). They are also known to form massive blooms in river deltas and semi-enclosed basins such as the Baltic Sea (Stal et al., 1999; Larsson et al., 2001). Their dominant role in the primary production of freshwater and brackish environments is related to their unique ability to simultaneously perform oxygenic photosynthesis and nitrogen fixation, enabling them to outcompete eukaryotic algae under nitrogen limiting conditions (Levine and Schindler, 1999). For this, heterocystous cyanobacteria confine the fixation of $\mathrm{N}_{2}$ to heterocysts, which host the oxygen-sensitive enzyme nitrogenase that catalyzes the reduction of dinitrogen gas to ammonia. These specialized cells are enveloped in a set of unique glycolipids, so-called heterocyst glycolipids (HGs), which are exclusively present in $\mathrm{N}_{2}$-fixing heterocystous cyanobacteria (Nichols and Wood, 1968; Gambacorta et al., 1999; Bauersachs et al., 2009a) and are considered to act as a gas diffusion barrier that limits the entry of oxygen into the heterocyst (Wolk, 1982). These components are composed of sugar head groups that are glycosidically bound to long-chain diols, triols, keto-ols or keto-diols with an even carbon chain ranging from $\mathrm{C}_{26}$ to $\mathrm{C}_{32}$ carbon atoms (Fig. 1). The distribution of HG diols and keto-ols has previously been shown to strongly correlate with growth temperature in cultures of the heterocystous cyanobacteria Anabaena CCY9613 and Nostoc CCY9926 (Bauersachs et al., 2009a, 2014). These authors demonstrated that in both types of cyanobacteria the relative proportion of $\mathrm{HG}$ diols significantly increased compared to their corresponding HG keto-ols with increasing growth temperature and introduced the $\mathrm{HG}_{26}$ (heterocyst glycolipid index of 26 carbon atoms) and $\mathrm{HG}_{28}$ (heterocyst glycolipid index of 28 carbon atoms) as means to quantify structural changes in the HG composition of the heterocyst cell envelope. It should be pointed out though that the overall change in the structural composition of the heterocyst cell envelope varied significantly between both cyanobacteria with $\mathrm{HG}_{26}$ values ranging from 0.10 to 0.18 in Anabaena CCY9613 and from 0.12 to 0.30 in Nostoc CCY9926 (Bauersachs et al., 2014), indicating that individual species of heterocystous cyanobacteria may tune the properties of the gas diffusion barrier in a slightly different fashion. Nonetheless, the finding of temperature-induced changes in the heterocyst glycolipid composition of $\mathrm{N}_{2}$-fixing heterocystous cyanobacteria may offer the exciting possibility to reconstruct surface water temperatures of modern and possibly also fossil lacustrine environments given that (1) heterocystous cyanobacteria are a common component of the phytoplankton community in many contemporary and fossil freshwater environments (Whitton, 2012) and (2) HGs have been shown to preserve well in the geological record (Bauersachs et al., 2010). Here, we investigated temporal variations in the distribution of heterocyst glycolipids in water column filtrates of Lake Schreventeich (Kiel, Germany). We also analyzed the distribution of HGs in the lake's surface sediments and discuss the potential use of HGs in the reconstruction of surface water temperatures in modern and fossil freshwater environments.

\section{Material and methods}

\subsection{Study site and sampling}

Lake Schreventeich is a small holomictic lake situated in northern Germany $\left(54^{\circ} 19^{\prime} 36.79^{\prime \prime} \mathrm{N}, 10^{\circ} 07^{\prime} 17.57^{\prime \prime} \mathrm{E}\right)$. Its surface area covers approximately $0.38 \mathrm{~km}^{2}$ and it has an average depth of 1.4-1.6 m (maximum depth of $3.4 \mathrm{~m}$ ). The 

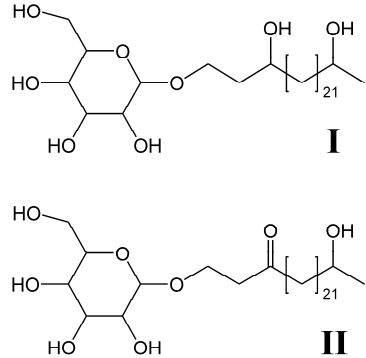
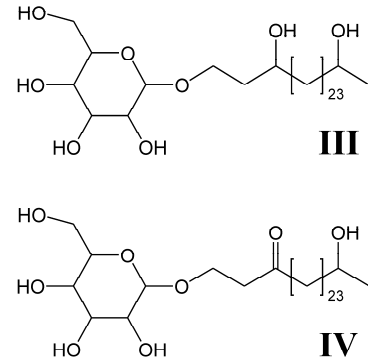
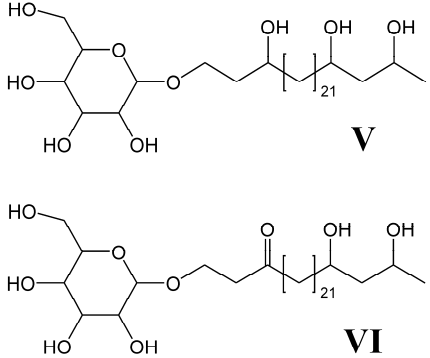

Figure 1. Structures of heterocyst glycolipids detected in water column filtrates and surface sediments of Lake Schreventeich. 1-(Ohexose)-3,25-hexacosanediol (I), 1-(O-hexose)-3-keto-25-hexacosanol (II), 1-(O-hexose)-3,27-octacosanediol (III), 1-(O-hexose)-3-keto-27octacosanol (IV), 1-(O-hexose)-3,25,27-octacosanetriol (V) and 1-(O-hexose)-3-keto-25,27-octacosanediol (VI).

lake has no tributaries and is solely fed by precipitation and ground water inflow.

Surface water samples for the analysis of HGs were taken from late July to the end of October 2013. Oxygen concentrations and surface water temperatures were measured at time of sampling using the portable oxygen measuring instrument Oxi 1970i coupled to a CellOx325 oxygen probe (WTW, Germany). The $\mathrm{pH}$ of all water samples was determined using a FG2-FiveGo (Mettler-Toledo, Germany) using a twopoint calibration on certified reference solutions obtained from Hanna Instruments. Surface sediments $(0-1 \mathrm{~cm})$ from two locations within Lake Schreventeich were obtained in March 2014 using a Uwitec gravity corer (Uwitec, Switzerland). All sediments were freeze-dried and ground to a homogenous powder using pestle and mortar.

\subsection{Determination of algal biomass}

A total of $100 \mathrm{~mL}$ of surface water was collected during each sampling and filtered over a preweighed Whatman filter GF/C $(1.2 \mu \mathrm{m}$, diameter $47 \mathrm{~mm})$. After filtration, filters were manually inspected and non-phytoplankton biomass was removed using a pair of tweezers. All filters were subsequently dried in an oven at $105^{\circ} \mathrm{C}$ for $24 \mathrm{~h}$. Phytoplankton biomass was calculated as the weight difference between the preweighed and the oven-dried filters.

\subsection{Bligh and Dyer extraction of water column filtrates and core top sediments}

Measured volumes (e.g., 3-4 L) of surface water were filtered through a MN 85/70 BF (binder free) glass fiber filter with a pore size of $0.45 \mu \mathrm{m}$ (Macherey-Nagel, Germany). All filters were freeze-dried and extracted following a modified Bligh and Dyer procedure as described by Rütters et al. (2002). Briefly, filters were cut into fine pieces with a solvent-cleaned scissor and ultrasonically extracted using a solvent mixture of methanol $(\mathrm{MeOH})$, dichloromethane (DCM) and phosphate buffer $(2: 1: 0.8 ; v / v / v)$. After centrifugation, the supernatant was collected and the residue extracted twice with the solvent mixture specified above. DCM and phosphate buffer were added to the pooled supernatants to achieve a ratio of $\mathrm{MeOH} / \mathrm{DCM} /$ phosphate buffer of $1: 1: 0.9(v / v / v)$, allowing the separation of two phases. The bottom layer, containing the organic fraction, was transferred to a glass vial and the remaining aqueous phase was extracted twice with DCM. The combined extracts were reduced under rotary vacuum, transferred to preweighed vials and dried under a gentle stream of $\mathrm{N}_{2}$. All Bligh and Dyer extracts were subsequently dissolved in $\mathrm{DCM} / \mathrm{MeOH}(9: 1 ; v / v)$ to a concentration of $2-4 \mathrm{mg} \mathrm{mL}^{-1}$ and filtered through a $0.45 \mu \mathrm{m}$ pore size, regenerated cellulose filter (13 mm; LLG Labware, Germany) prior to analysis. In addition to water column filtrates, $0.5 \mathrm{~g}$ of freeze-dried core top sediments obtained from Lake Schreventeich were extracted using the procedure outlined above.

\subsection{Analysis of heterocyst glycolipids}

Heterocyst glycolipids were analyzed following the procedure described by Bauersachs et al. (2014) with some brief modifications. Separation of the target compounds was achieved using an Alliance 2690 HPLC (high-performance liquid chromatography) system (Waters, UK) fitted with a Luna Hilic 200A column $(150 \mathrm{~mm} \times 2 \mathrm{~mm}$ inner diameter; $3 \mu \mathrm{m}$ particle size; Phenomenex, Germany) maintained at $30^{\circ} \mathrm{C}$. The following linear gradient was used with a flow rate of $0.2 \mathrm{~mL} \mathrm{~min}^{-1}: 95 \%$ eluent $\mathrm{A} / 5 \%$ eluent $\mathrm{B}$ to $70 \%$ $\mathrm{A} / 30 \% \mathrm{~B}$ in $10 \mathrm{~min}$ (held $20 \mathrm{~min}$ ), followed by $70 \% \mathrm{~A} / 30 \%$ $\mathrm{B}$ to $35 \% \mathrm{~A} / 65 \% \mathrm{~B}$ in $15 \mathrm{~min}$ (held $15 \mathrm{~min}$ ), then back to $95 \% \mathrm{~A} / 5 \% \mathrm{~B}$ in $1 \mathrm{~min}$ (held $20 \mathrm{~min}$ ) to re-equilibrate the column. Eluent A was hexane/isopropanol/formic acid $/ 14.8 \mathrm{M}$ aqueous $\mathrm{NH}_{3}(79: 20: 0.12: 0.04 ; v / v / v / v)$ and eluent B was isopropanol/water/formic acid/14.8 M aqueous $\mathrm{NH}_{3}(88: 10: 0.12: 0.4 ; v / v / v / v)$.

Detection of heterocyst glycolipids was accomplished using a Quattro LC triple quadrupole mass spectrometer (Micromass, UK). The positive electrospray ionization (ESI) conditions were as follows: capillary voltage, $3.2 \mathrm{kV}$; cone voltage, $25 \mathrm{~V}$; source temperature, $120^{\circ} \mathrm{C}$; desolvation temperature, $200^{\circ} \mathrm{C}$; cone gas flow, $1 \mathrm{~L} \mathrm{~min}^{-1}$; and desolvation gas flow, $4 \mathrm{~L} \mathrm{~min}^{-1}$. To qualitatively determine the distri- 
bution of HGs in water column filtrates of Lake Schreventeich, all Bligh and Dyer extracts were analyzed in datadependent mode with two scan events, where a positive ion scan $(m / z, 300-1000)$ was followed by a product ion scan of the base peak of the mass spectrum of the first scan event. Identification of HGs was based on comparison with published mass spectra (Bauersachs et al., 2009b). To improve the sensitivity of the measurement and therewith increase reproducibility, HGs were also detected via single ion recording (SIR) of their protonated molecules $[\mathrm{M}+\mathrm{H}]^{+}$(dwell time $234 \mathrm{~ms}$ ) with $m / z 575.5$ ( $\mathrm{HG}_{26}$ keto-ol), $m / z 577.5\left(\mathrm{HG}_{26}\right.$ diol), $m / z 603.5$ ( $\mathrm{HG}_{28}$ keto-ol), $m / z 605.5$ ( $\mathrm{HG}_{28}$ diol), $m / z 619.5$ ( $\mathrm{HG}_{28}$ keto-diol) and $m / z 621.5$ ( $\mathrm{HG}_{28}$ triol). Selected samples were analyzed in duplicate and fractional abundances of HGs as well as calculated HG ratios (e.g., $\mathrm{HDI}_{26}, \mathrm{HDI}_{28}, \mathrm{HTI}_{28}$ ) given in the text represent average values of these measurements. Quantification was done by integration of the peak area using the QuanLynx application manager.

\section{Results}

\subsection{Variation of environmental parameters and algal biomass in Lake Schreventeich}

Physical and biological data of Lake Schreventeich collected from late July to the end of October 2013 are summarized in Fig. 2. All investigated physical parameters (i.e., temperature, oxygen concentration and $\mathrm{pH}$ ) show maxima in late July or at the beginning of August and gradually decline to yield minima in late October. Surface water temperatures ranged from 10.5 to $24.0^{\circ} \mathrm{C}$ and were highest in late July (Fig. 2a). Oxygen concentrations in the surface waters varied from 2.5 to $7.6 \mathrm{mg} \mathrm{L}^{-1}$ with highest values occurring in late July and they subsequently declined over the investigated time interval to yield minimum values in late October (Fig. 2b). The $\mathrm{pH}$ values ranged from 7.18 to 7.79 and were comparatively high during the first half of the sampling campaign with values averaging 7.56 in August (Fig 2c). In contrast, the $\mathrm{pH}$ showed a significant drop by almost 0.2 units at the beginning of September and stayed around 7.32 throughout the first half of September before increasing again to values of ca. 7.50 at the beginning of October. Lake productivity was determined by measuring the amount of biomass present at time of sampling. Comparatively low amounts of biomass were found in late July with values of $11.6 \mathrm{mg} \mathrm{L}^{-1}$ that almost doubled in August with an average value of $20.7 \mathrm{mg} \mathrm{L}^{-1}$ (Fig. 2d). After a pronounced peak in the first half of September (maximum $50.1 \mathrm{mg} \mathrm{L}^{-1}$; average $35.3 \mathrm{mg} \mathrm{L}^{-1}$ ), biomass concentrations declined to an average value of $22.5 \mathrm{mg} \mathrm{L}^{-1}$ in October.

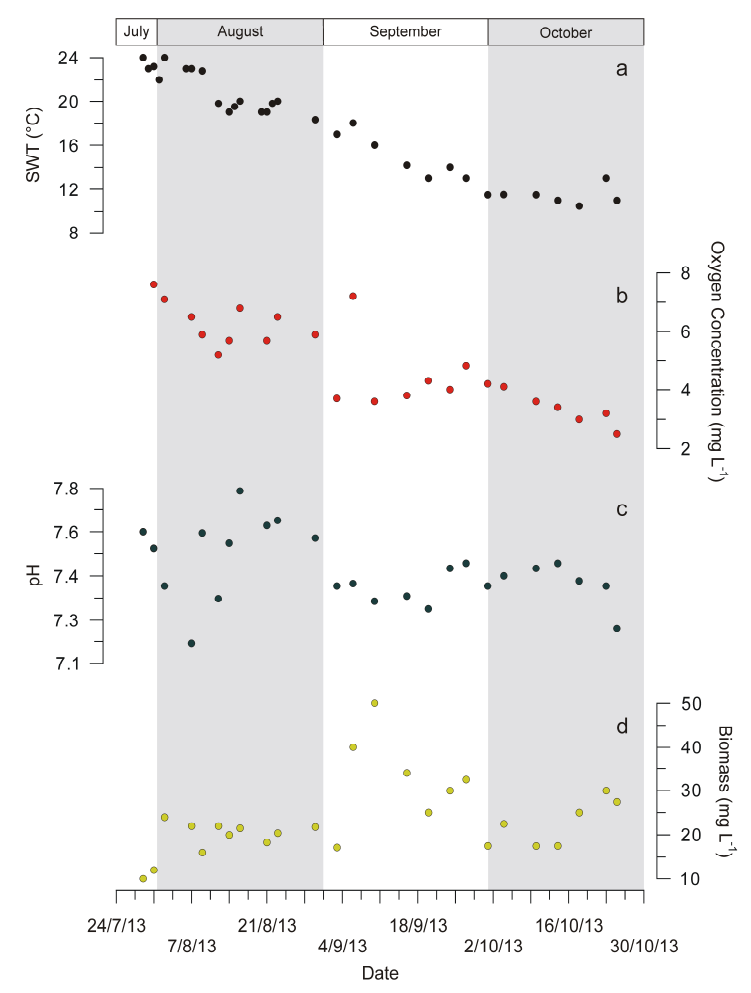

Figure 2. (a) Surface water temperature (SWT), (b) oxygen concentration, (c) $\mathrm{pH}$ and (d) amount of phytoplankton biomass measured in Lake Schreventeich from late July until the end of October 2013.

\subsection{Distribution and fractional abundances of heterocyst glycolipids in water column filtrates of Lake Schreventeich}

Heterocyst glycolipids were below detection limit in late July and early August. They were first identified in mid-August in relatively low abundances and gradually increased in late August to reach peak abundances in early to mid-September (Fig. 3). In late September, the relative abundance of HGs declined to reach comparatively low but constant values from mid- to late October. As shown in Fig. S1 in the Supplement, two structural isomers of 1-(O-hexose)-3,25-hexacosanediol ( $\mathrm{HG}_{26}$ diol) and 1-(O-hexose)-3-keto-25-hexacosanol ( $\mathrm{HG}_{26}$ keto-ol) generally dominated the HG pool and together they constituted $71-100 \%$ (average $82.7 \pm 7.2 \%$ ) of all heterocyst glycolipids over the investigated time interval. The early eluting $\mathrm{HG}_{26}$ diol, however, generally constituted only a minute fraction of all HGs (on average $<0.5 \%$ ). The heterocyst glycolipids 1-(O-hexose)-3,25,27-octacosanetriol $\left(\mathrm{HG}_{28}\right.$ triol) and 1-(O-hexose)-3-keto-25,27-octacosanediol $\left(\mathrm{HG}_{28}\right.$ keto-diol) were particularly abundant in late August with fractional abundances of up to $25 \%$ but in general they contributed $6-17 \%$ (average $12.3 \pm 6.2 \%$ ) to the heterocyst glycolipid content of Lake Schreventeich. 1-(O-hexose)3,27-octacosanediol ( $\left.\mathrm{HG}_{28} \mathrm{diol}\right)$ and 1-(O-hexose)-3-keto27 -octacosanol $\left(\mathrm{HG}_{28}\right.$ keto-ol) were below detection limit in 


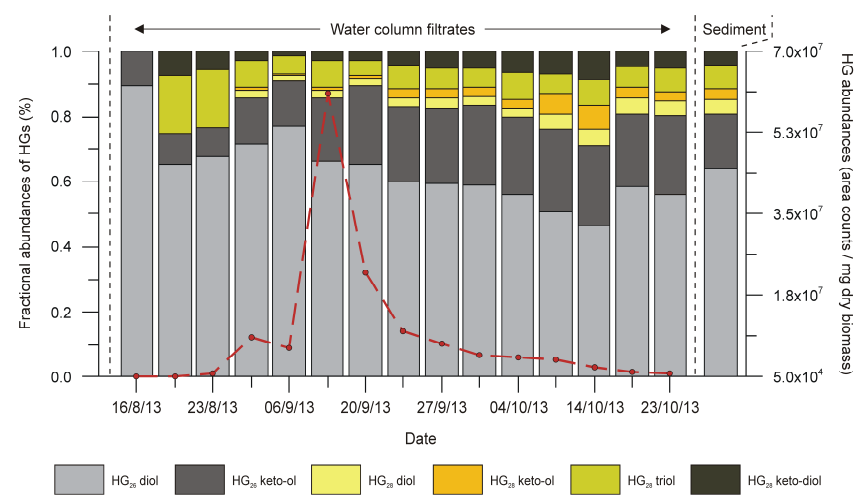

Figure 3. Fractional abundances of HGs in surface waters of Lake Schreventeich. Dashed line indicates relative abundances of the sum of all heterocyst glycolipids normalized to the amount of phytoplankton biomass over the investigated time interval. Note that heterocyst glycolipids were not detected in water column filtrates taken before mid-August. Fractional abundances of HGs in the sediment of Lake Schreventeich represent average values obtained from the analysis of two core top samples.

water column filtrates taken before early September (Fig. 3) and they usually constituted a minor component of the total HG pool with fractional abundances of both compounds ranging from 0 to $13 \%$ (average $4.9 \pm 3.8 \%$ ).

It is interesting to note that the fractional abundance of all HG diols and triols declined over the investigated time interval, while the fractional abundance of their corresponding keto-ol and keto-diol varieties showed a concomitant increase (Fig. 3). For example, the fractional abundance of the $\mathrm{HG}_{26}$ diol was highest (> 70\%) in late August to early September and thereafter declined gradually to yield values around $50 \%$ at the end of October. Over the same time period, the fractional abundance of the $\mathrm{HG}_{26}$ keto-ol significantly increased from $9 \%$ at the end of August to $25 \%$ in late October. Overall, similar trends were also observed for the $\mathrm{HG}_{28}$ triol and $\mathrm{HG}_{28}$ keto-diol as well as for the $\mathrm{HG}_{28}$ diol and $\mathrm{HG}_{28}$ keto-ol. It should be pointed out though that for the $\mathrm{HG}_{28}$ diol and the $\mathrm{HG}_{28}$ keto-ol this trend was less apparent, which may be due to the low analytical response and the resulting uncertainties in determining the contribution of both components to the total HG pool.

\subsection{Distribution and fractional abundances of heterocyst glycolipids in surface sediments of Lake Schreventeich}

The distribution of HGs in surface sediments of Lake Schreventeich largely resembled those observed in the water column filtrates with the $\mathrm{HG}_{26}$ diol and $\mathrm{HG}_{26}$ keto-ol being most abundant (Fig. 3). Both components constituted ca. $81 \%$ of the total $\mathrm{HG}$ pool with $\mathrm{HG}_{26}$ diol and $\mathrm{HG}_{26}$ keto-ol accounting for 64 and $17 \%$ of all HGs, respectively. $\mathrm{HG}_{28}$ triol and $\mathrm{HG}_{28}$ keto-diol were the second most abun- dant types of HGs in Lake Schreventeich sediments, contributing 7 and $4 \%$ of all HGs. Similar to the distribution of HGs in the water column filtrates, $\mathrm{HG}_{28}$ diol and $\mathrm{HG}_{28}$ ketool constituted only minor components of the HG pool with 5 and $3 \%$, respectively. Fractional abundances of HGs found in the core top sediments of Lake Schreventeich are thus well in line with those observed in water column filtrates, in particular with those obtained in mid-September.

\section{Discussion}

\subsection{Sources and environmental controls on the HG distribution in water column filtrates of Lake Schreventeich}

Heterocyst glycolipids were below the detection limit in water column filtrates collected throughout July to early August and were first observed in mid-August. In general, the distribution of heterocyst glycolipids in Lake Schreventeich is well in line with those previously reported from nostocalean cyanobacteria (Bauersachs et al., 2009a; Wörmer et al., 2012) and likely suggests that members of the genera $A n$ abaena and/or Aphanizomenon were part of the phytoplankton community of Lake Schreventeich in late summer 2013. This agrees well with microbiological studies of the phytoplankton community of other lakes in northern Germany, for which representatives of both genera have indeed been reported in abundance (Arp et al., 2013). The simultaneous increase in total $\mathrm{HG}$ abundances and aquatic biomass in early to mid-September (Figs. 2 and 3) may also suggest that heterocystous cyanobacteria constituted a significant component of the lake's phytoplankton.

We observed systematic changes in the distribution of heterocyst glycolipids in water column filtrates of Lake Schreventeich over the time interval investigated. The most apparent was a systematic decline in the fractional abundances of HG diols and the HG triol from mid-August to late October, which was significantly positively correlated with surface water temperature (Table 1). On the contrary, fractional abundances of HG keto-ols and keto-diols gradually increased from late August to the end of the sampling campaign. This increase in fractional abundances was significantly negatively correlated with changes in surface water temperatures (Table 1). Similar changes in the fractional abundances of $\mathrm{HG}_{26}$ and $\mathrm{HG}_{28}$ diols and keto-ols with growth temperature have previously been described from cultures of the $\mathrm{N}_{2}$-fixing heterocystous cyanobacteria Anabaena CCY9613 and Nostoc CCY9926 (Bauersachs et al., 2009a, 2014) and been explained as a physiological adaptation to compensate for greater gas diffusion rates of $\mathrm{O}_{2}$ at higher temperatures in order to keep the entry of atmospheric gases into the heterocyst at a minimum, which is considered a prerequisite for optimum $\mathrm{N}_{2}$ fixation. To quantitatively express these structural changes of the heterocyst cell envelope, 
Table 1. Correlations of fractional abundances $(F)$ of individual heterocyst glycolipids and heterocyst glycolipid indices with SWT, oxygen concentration, $\mathrm{pH}$ and biomass. Significant correlations were observed, among others, between fractional abundances of heterocyst glycolipids and SWT as well as between the different HG indices and SWT. Note that certain environmental parameters were also positively correlated with each other. Significant correlations are indicated in bold. $r=$ correlation coefficient; $p=p$ value.

\begin{tabular}{|c|c|c|c|c|c|}
\hline Parameter & & $\begin{array}{l}\text { SWT } \\
\left({ }^{\circ} \mathrm{C}\right)\end{array}$ & $\begin{array}{l}\text { Oxygen Con. } \\
\quad\left(\mathrm{mg} \mathrm{L}^{-1}\right)\end{array}$ & $\mathrm{pH}$ & $\begin{array}{r}\text { Biomass } \\
\left(\mathrm{mg} \mathrm{L}^{-1}\right)\end{array}$ \\
\hline \multirow[t]{2}{*}{$F_{\text {HG26 diol }}$} & $r$ & 0.807 & 0.746 & 0.424 & 0.216 \\
\hline & $p$ & 0.000 & 0.001 & 0.115 & 0.439 \\
\hline \multirow[t]{2}{*}{$F_{\text {HG26 keto-ol }}$} & $r$ & -0.954 & -0.777 & -0.671 & 0.027 \\
\hline & $p$ & 0.000 & 0.001 & 0.006 & 0.925 \\
\hline \multirow[t]{2}{*}{$F_{\mathrm{HG} 28 \text { diol }}$} & $r$ & -0.714 & -0.621 & 0.494 & -0.444 \\
\hline & $p$ & 0.009 & 0.031 & 0.103 & 0.148 \\
\hline \multirow[t]{2}{*}{$F_{\mathrm{HG} 28 \text { keto-ol }}$} & $r$ & -0.715 & -0.467 & 0.624 & -0.571 \\
\hline & $p$ & 0.009 & 0.126 & 0.030 & 0.052 \\
\hline \multirow[t]{2}{*}{$F_{\mathrm{HG} 28 \text { triol }}$} & $r$ & 0.680 & 0.445 & 0.856 & -0.257 \\
\hline & $p$ & 0.007 & 0.111 & 0.000 & 0.374 \\
\hline \multirow{2}{*}{$F_{\text {HG28 keto-diol }}$} & $r$ & -0.288 & -0.251 & 0.550 & -0.574 \\
\hline & $p$ & 0.318 & 0.387 & 0.042 & 0.032 \\
\hline \multirow[t]{2}{*}{$\mathrm{HDI}_{26}$} & $r$ & 0.962 & 0.803 & 0.591 & 0.070 \\
\hline & $p$ & 0.000 & 0.000 & 0.020 & 0.805 \\
\hline \multirow[t]{2}{*}{$\mathrm{HDI}_{28}$} & $r$ & 0.835 & 0.530 & -0.590 & 0.624 \\
\hline & $p$ & 0.001 & 0.077 & 0.044 & 0.030 \\
\hline \multirow[t]{2}{*}{$\mathrm{HTI}_{28}$} & $r$ & 0.884 & 0.646 & 0.109 & 0.451 \\
\hline & $p$ & 0.000 & 0.013 & 0.711 & 0.105 \\
\hline \multirow[t]{2}{*}{$\operatorname{SWT}\left({ }^{\circ} \mathrm{C}\right)$} & $r$ & & 0.866 & 0.335 & -0.316 \\
\hline & $p$ & & 0.000 & 0.101 & 0.124 \\
\hline \multirow[t]{2}{*}{ Oxygen Con. (mg L $\left.{ }^{-1}\right)$} & $r$ & & & 0.430 & -0.232 \\
\hline & $p$ & & & 0.036 & 0.275 \\
\hline \multirow[t]{2}{*}{$\mathrm{pH}$} & $r$ & & & & -0.415 \\
\hline & $p$ & & & & 0.039 \\
\hline
\end{tabular}

Bauersachs et al. (2009a) introduced the $\mathrm{HG}_{26}$ index (heterocyst glycolipid index of 26 carbon atoms), which is defined as

$\mathrm{HG}_{26}=\mathrm{HG}_{26}$ keto-ol $/\left(\mathrm{HG}_{26}\right.$ diol $+\mathrm{HG}_{26}$ keto-ol $)$

This notation, however, is somewhat counterintuitive as values of the $\mathrm{HG}_{26}$ index decline with increasing growth temperature. Therefore, we here used the $\mathrm{HDI}_{26}$ (heterocyst diol index of 26 carbon atoms), which in contrast to the $\mathrm{HG}_{26}$ index is positively correlated with temperature and defined as given below. It should be pointed out though that the $\mathrm{HG}_{26}$ index and the $\mathrm{HDI}_{26}$ have the same statistical significance.

$$
\begin{aligned}
& \mathrm{HDI}_{26}=\mathrm{HG}_{26} \text { diol } /\left(\mathrm{HG}_{26} \text { keto-ol }+\mathrm{HG}_{26} \text { diol }\right) \\
& \mathrm{HDI}_{26}=0.0224 \times \mathrm{SWT}+0.4381 ; r^{2}=0.93
\end{aligned}
$$

In Lake Schreventeich, $\mathrm{HDI}_{26}$ values ranged from 0.89 in mid-August to 0.66 in late October (Fig. 4) and closely followed variations in surface water temperatures (Fig. S2 in the Supplement). For example, $\mathrm{HDI}_{26}$ values gradually declined over the investigated time period until mid-October and afterwards slightly increased again, in agreement with a rise in measured surface water temperature in late Octo- ber. Least squares analysis of the data showed that variations in $\mathrm{HDI}_{26}$ values are strongly linearly correlated with surface water temperatures. As the $\mathrm{HG}_{28}$ diol and keto-ol as well as the $\mathrm{HG}_{28}$ triol and keto-diol showed similar changes in fractional abundances compared to the $\mathrm{HG}_{26}$ diol and the $\mathrm{HG}_{26}$ keto-ol, we also employed the $\mathrm{HDI}_{28}$ (heterocyst diol index of 28 carbon atoms) and the $\mathrm{HTI}_{28}$ (heterocyst triol index of 28 carbon atoms) in order to quantitatively determine changes in HG distributions with environmental parameters. Both indices were calculated as given in the following equations:

$$
\begin{aligned}
& \mathrm{HDI}_{28}=\mathrm{HG}_{28} \text { diol } /\left(\mathrm{HG}_{28} \text { keto-ol }+\mathrm{HG}_{28} \text { diol }\right), \\
& \mathrm{HDI}_{28}=0.0405 \times \mathrm{SWT}+0.0401 ; r^{2}=0.70, \\
& \mathrm{HTI}_{28}=\mathrm{HG}_{28} \text { triol } /\left(\mathrm{HG}_{28} \text { keto-diol }+\mathrm{HG}_{28} \text { triol }\right), \\
& \mathrm{HTI}_{28}=0.0288 \times \mathrm{SWT}+0.2292 ; r^{2}=0.78 .
\end{aligned}
$$

Similar to the $\mathrm{HDI}_{26}$, the $\mathrm{HDI}_{28}$ and the $\mathrm{HTI}_{28}$ closely followed measured surface water temperatures with absolute values of these indices gradually declining over the investigated time period from 0.82 to 0.42 and from 0.81 to 0.49 , respectively (Fig. 4). Least squares analysis of the data demon- 

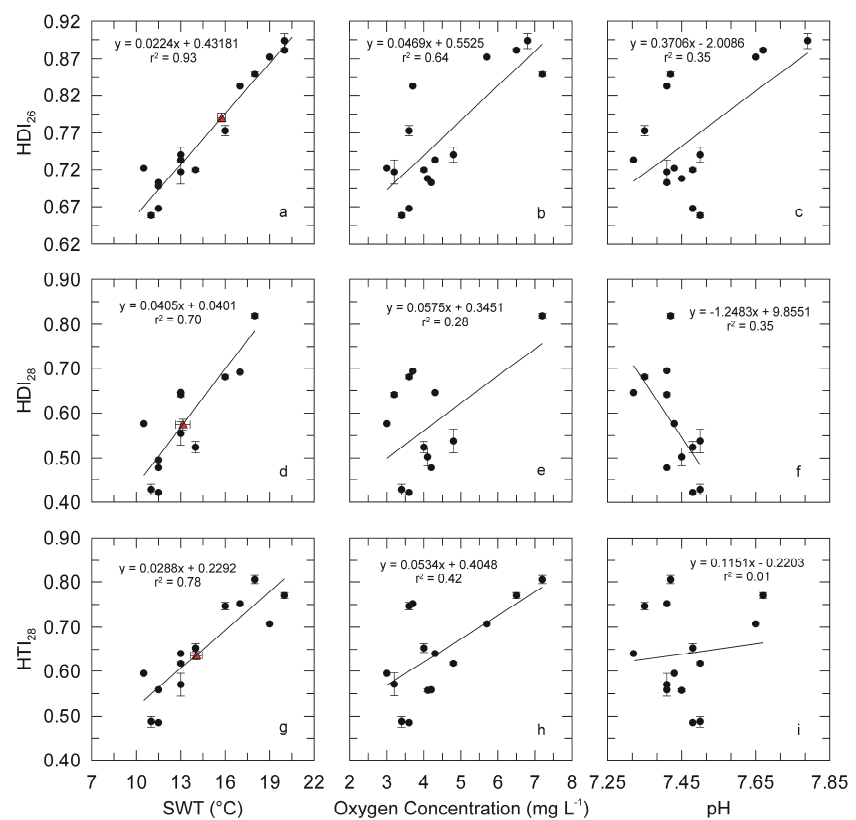

Figure 4. Cross-plots of the $\mathrm{HDI}_{26}$ (a-c), $\mathrm{HDI}_{28}$ (d-f) and $\mathrm{HTI}_{28}$ (g-i) obtained from water column filtrates with measured SWT, oxygen concentration and $\mathrm{pH}$ of Lake Schreventeich's surface waters. Red triangles represent $\mathrm{HDI}_{26}{ }^{-}, \mathrm{HDI}_{28^{-}}$and $\mathrm{HTI}_{28^{-}}$ reconstructed SWTs obtained from the analysis of surface sediments of Lake Schreventeich.

strates that both indices are significantly correlated with surface water temperatures, although correlations are generally less strong as compared to the $\mathrm{HDI}_{26}$. All three $\mathrm{HG}$ indices, however, seem to track temperature changes in the lake's surface waters in a similar fashion, albeit with slight differences in absolute values and trends between the individual indices (see Fig. S2 in the Supplement). One explanation for the slight offsets between the individual indices may be the contribution of heterocyst glycolipids from different cyanobacterial sources. Bauersachs et al. (2009a, 2014) as well as Wörmer et al. (2012) noticed that fractional abundances of heterocyst glycolipids may vary between different genera of heterocystous cyanobacteria and even within heterocystous cyanobacteria belonging to the same genus. Moreover, Bauersachs et al. (2014) observed that fractional abundances of $\mathrm{HG}_{26}$ and $\mathrm{HG}_{28}$ diols and keto-ols changed differently in Anabaena CCY9613 and Nostoc CCY9926, resulting in slightly deviating $\mathrm{HG}_{26}$ and $\mathrm{HG}_{28}$ values for each of the investigated species. As multiple members of heterocystous cyanobacteria (e.g., Anabaena and Aphanizomenon), adapting the composition of the heterocyst cell envelope in slightly different fashions, likely contributed to the total pool of HGs in Lake Schreventeich, absolute values of the different HG indices may have varied depending on the amount of heterocyst glycolipids contributed by each individual cyanobacterium. In this context it is interesting to note that the different HG indices show a similar trend with surface water tem- peratures but that $\mathrm{HDI}_{26}$ values are generally higher compared to $\mathrm{HDI}_{28}$ and $\mathrm{HTI}_{28}$ values, resulting in a deviation from the $1: 1$ line as shown in Fig. S3. $\mathrm{HDI}_{28}$ and $\mathrm{HTI}_{28}$ values, on the contrary, are very similar to each other and fall close to the $1: 1$ line, indicating that they may have the same biological origin.

When the different HG indices are plotted against environmental parameters other than surface water temperatures (Fig. 4), it is apparent that the $\mathrm{HDI}_{26}(p<0.001$; $\left.r^{2}=0.64\right)$ and the $\operatorname{HTI}_{28}\left(p<0.05 ; r^{2}=0.42\right)$ are positively correlated with decreasing oxygen concentrations and that the $\mathrm{HDI}_{26}\left(p<0.05 ; r^{2}=0.35\right)$ and the $\mathrm{HDI}_{28}(p<0.05$; $\left.r^{2}=0.35\right)$ also show a weak positive correlation with $\mathrm{pH}$. However, these correlations are generally less significant and not as strong as observed for the correlation with surface water temperatures. It should also be noted that oxygen concentrations and $\mathrm{pH}$ are strongly correlated with surface water temperatures and that both parameters show a positive correlation with each other (Table 1). Therefore, the observed correlations between the different HG indices and oxygen concentrations as well as $\mathrm{pH}$ are likely indirect rather than indicating a statistically significant relationship between the individual environmental parameters and changes in the heterocyst glycolipid distribution. However, Kangatharalingam et al. (1992) reported that the heterocyst cell envelope of Anabaena flos-aquae increased in thickness when this cyanobacterium was grown under increased levels of oxygen stress and it can therefore not be excluded that environmental factors other than growth temperature may affect the distribution of heterocyst glycolipids in heterocystous cyanobacteria (although these authors did not analyze changes in the chemical structure of the heterocyst cell envelope). Additional investigations employing culture-dependent approaches and studying the effect of environmental parameters other than growth temperature will be needed to elucidate whether and to which extent oxygen concentrations and $\mathrm{pH}$ exert a control on the structural composition of the heterocyst cell envelope of heterocystous cyanobacteria.

\subsection{Accuracy of surface water reconstructions based on HG indices}

The accuracy with which surface water temperatures of a given aquatic environment can be reconstructed is essential for any novel lipid thermometer. Based on replicate analysis of individual water column filtrates and surface sediments, the average analytical precision with which the $\mathrm{HDI}_{26}$ can be determined is \pm 0.006 . Using the respective temperature calibration (see Eq. 3), this equals a standard error in temperature estimates of $\pm 0.27^{\circ} \mathrm{C}$. The determination of $\mathrm{HDI}_{28}( \pm 0.012)$ and $\mathrm{HTI}_{28}( \pm 0.010)$ values is slightly less accurate than for $\mathrm{HDI}_{26}$, which may be due to the lower abundance of $\mathrm{HG}_{28}$ diols, triols, keto-ols and keto-diols in the analyzed water column filtrates, with the standard error in temperature estimates 
being $\pm 0.30{ }^{\circ} \mathrm{C}$ for the $\mathrm{HDI}_{28}$ and $\pm 0.34^{\circ} \mathrm{C}$ for the $\mathrm{HTI}_{28}$. However, the overall analytical precision in the analysis of the different HG indices is of the same order of magnitude or even slightly better when compared to other well-established temperature proxies, such as the $\mathrm{TEX}_{86}$ and $\mathrm{U}_{37}^{\mathrm{K}^{\prime}}$, and indicates that reconstructions of surface water temperatures using the $\mathrm{HDI}_{26}$ and other $\mathrm{HG}$ indices may be achieved with a relatively high accuracy. This is also suggested by analysis of the residual errors of the HG-estimated SWTs (calculated SWTs - measured SWTs), which are generally $<2{ }^{\circ} \mathrm{C}$ with mean standard errors of $0.97,1.62$ and $1.69^{\circ} \mathrm{C}$ for $\mathrm{HDI}_{26}$ , $\mathrm{HDI}_{28}$ - and $\mathrm{HTI}_{28}$-reconstructed SWTs, respectively, and without following a clear trend with SWT (see Fig. S4 in the Supplement).

\subsection{Distribution of heterocyst glycolipids in Lake Schreventeich surface sediments}

In order to determine if the heterocyst glycolipid signal observed in the water column filtrates is transferred to the sedimentary realm, we also analyzed two surface sediments collected from Lake Schreventeich for their HG content. Sedimentary HG distributions were indeed very similar to those observed in water column filtrates with $\mathrm{HG}_{26}$ diol and $\mathrm{HG}_{26}$ keto-ol dominating over smaller quantities of $\mathrm{HG}_{28}$ triol and $\mathrm{HG}_{28}$ keto-diol as well as $\mathrm{HG}_{28}$ diol and $\mathrm{HG}_{28}$ keto-ol. It is interesting to note that the distribution of HGs in the two surface sediment samples most closely resembled the one observed during the period of maximum lake productivity and peak abundances of HGs in early to mid-September (Figs. 2, 3 ), suggesting that the preserved HGs were mainly produced during maximum activity of heterocystous cyanobacteria in Lake Schreventeich. $\mathrm{HDI}_{26}$ values of surface sediments from Lake Schreventeich averaged $0.791 \pm 0.008$. Using the temperature calibration obtained from the analysis of the water column filtrates, the $\mathrm{HDI}_{26}$ value translates into an average surface water temperature of $15.8 \pm 0.3^{\circ} \mathrm{C}$. Considering the current accuracy for the detection of heterocyst glycolipids, the $\mathrm{HDI}_{26}$-based temperature reconstructed for Lake Schreventeich largely agrees with surface water temperatures measured from early to mid-September and thus during the time period of highest productivity of heterocystous cyanobacteria. Likewise, reconstructed surface water temperatures based on $\mathrm{HDI}_{28}(0.575 \pm 0.018)$ and $\mathrm{HTI}_{28}$ $(0.637 \pm 0.012)$ values, obtained from the analysis of surface sediments of Lake Schreventeich and using their respective temperature calibrations, are $13.1 \pm 0.4$ and $14.1 \pm 0.3{ }^{\circ} \mathrm{C}$, respectively. Although slightly lower than the $\mathrm{HDI}_{26}$-based SWT estimates, both values again agree well with surface water temperatures measured during mid-September. Together, these observations suggest that the analysis of sedimentary HGs may allow reconstructing summer surface water temperatures in Lake Schreventeich and possibly also other lacustrine environments with sufficient export and in- corporation of cyanobacterial-derived organic matter into the sediment.

Despite the good agreement between measured and reconstructed surface water temperatures, it should be pointed out that the recovered surface sediments most likely not only contained HGs produced during the investigated time interval but HG distributions probably reflect a time-integrated signal that covers several years. In addition, surface water temperatures of Lake Schreventeich are expected to vary over the course of a day and the obtained temperatures (though always recorded at the same time of the day) provide only a snapshot of the actual temperature variance of the lake. Parts of the uncertainties in the correlation of HG indices and surface water temperatures may in fact be related to the low number of diurnal temperature measurements but may be improved by continuous temperature logging of the lake's surface waters in future studies. As discussed above, contributions of HGs from heterocystous cyanobacteria with slightly different HG distribution patterns and absolute abundances of HGs may also result in the observed offsets between the HG-based SWT calculations. Nonetheless, the overall good agreement of HG distributions in surface sediments and water column filtrates seems to indicate that (1) HGs in Lake Schreventeich are largely produced in late summer, coinciding with blooms of heterocystous cyanobacteria, and that (2) HG-reconstructed surface water temperatures primarily reflect a summer signal in this temperate lake.

\subsection{Geochemical implications}

As mentioned previously, $\mathrm{N}_{2}$-fixing heterocystous cyanobacteria are a common component of the phytoplankton community in contemporary freshwater and brackish environments of polar to tropical latitudes, where they may form massive blooms during summer (Whitton, 2012). Likewise, HGs seem to be widely distributed in modern freshwater and brackish environments. They have been reported from surface sediments of several European and African lakes including Lake Ohrid, Lake Malawi and Lake Challa (Bauersachs et al., 2010) as well as in phytoplankton collected from a number of Spanish freshwater reservoirs (Wörmer et al., 2012). HG distributions dominated by $\mathrm{HG}_{26}$ diols and $\mathrm{HG}_{28}$ triols have been reported from core top sediments recovered from the Landsort Deep, Baltic Sea (Bauersachs et al., 2010). They have also been described in several microbial mats growing along the coast of the southern North Sea (Bauersachs et al., 2011; Bühring et al., 2014) and western Spitsbergen (Rethemeyer et al., 2010) as well as in an Icelandic hot spring (Bauersachs et al., 2013). A suite of $\mathrm{HG}_{26}-\mathrm{HG}_{28}$ diols, triols, keto-ols and keto-diols was detected in suspended particulate matter in the surface waters of 23 oligotrophic and eutrophic lakes in Minnesota and Iowa, USA (Schoon, 2013), while $\mathrm{HG}_{26}-\mathrm{HG}_{28}$ diols and keto-ols were present in variable abundances and distributions in microbial mats re- 
covered from Shark Bay, Western Australia (Bauersachs et al., unpublished data).

The remarkably strong linear correlations found for the distribution of HGs in water column filtrates of Lake Schreventeich and its surface water temperatures indicate that $\mathrm{HG}$ distributions, in form of the $\mathrm{HDI}_{26}$ and other $\mathrm{HG}$ indices, may be well suited to track changes in water temperatures of the photic zone in freshwater environments. The generally good agreement of HG indices obtained from core top sediments of Lake Schreventeich with summer surface water temperatures furthermore suggests that the distribution of sedimentary HGs may also record surface water temperatures of lacustrine settings over time. In addition, it may indicate that no or only little selective degradation of HGs (e.g., diols vs. keto-ols) upon sinking and transport through the water column as well as during the incorporation into the sediment record occurred in this shallow lake system. At this point, however, it cannot be ruled out that microbial reworking may bias the initially synthesized $\mathrm{HG}$ signal in deeper lakes. Hence, additional studies determining degradation rates of individual HGs as well as changes in the overall HG distribution patterns with water depth will be necessary in order to elucidate whether and to which extend the HG inventory of lakes experiences early diagenetic alteration. Likewise, only limited information on the preservation potential of HGs over geological timescales exists. These components have been reported from Pleistocene Mediterranean sapropels as well as lacustrine deposits from the Oligocene Lake Enspel and the Eocene Messel oil shale (Bauersachs et al., 2010), indicating that they may readily preserve in the sediment record. However, detailed studies investigating the preservation of HGs in sedimentary sequences and their stability under varying environmental conditions are currently missing but will be essential to determine the robustness of HGs as lipid paleothermometers.

It has previously been demonstrated that changes in the distribution of HGs as a function of growth temperature can vary significantly between different cyanobacterial species as reported for Anabaena CCY9613 and Nostoc CCY9928 (Bauersachs et al., 2014). A finding that we confirmed for other nostocalean cyanobacteria such as Aphanizomenon sp. and Nodularia sp. in recent culture experiments (Bauersachs et al., unpublished data). The application of $\mathrm{HDI}_{26}$ and other HG-based indices may thus potentially be biased in lakes that are characterized by simultaneous growth of multiple species of heterocystous cyanobacteria, each modifying the composition of the heterocyst cell envelope in a slightly different fashion. It should also be pointed out that core top calibrations may not be applicable to accurately determine surface water temperatures in lake environments, in which the cyanobacterial community gradually changed over time.

\section{Conclusion}

The presence of heterocyst glycolipids in core top sediments of Lake Schreventeich, the overall good agreement of HGbased temperature estimates with measured surface water temperatures and the ubiquitous distribution of heterocystous cyanobacteria in modern freshwater and brackish environments, suggests that the $\mathrm{HDI}_{26}$ and other HG-based indices may hold great promise as proxies for the reconstruction of surface water temperatures in modern and possibly also fossil lacustrine environments, something that is currently not achieved by any other organic geochemical proxy. As heterocyst glycolipids constitute highly specific biological markers for diazotrophic heterocystous cyanobacteria, they also allow for a direct study of the overall impact of surface water temperature changes on the cyanobacterial community structure of a given lake system. However, additional analyses of HG distributions in freshwater environments in combination with environmental parameters (such as water temperatures, oxygen concentrations, $\mathrm{pH}$, light intensities, etc.) and molecular studies are clearly needed to evaluate the potential use of HG-based proxies in the determination of lacustrine surface water temperatures on a larger scale.

\section{The Supplement related to this article is available online at doi:10.5194/bg-12-3741-2015-supplement.}

Author contributions. T. Bauersachs and L. Schwark designed the experiments. J. Rochelmeier was involved in sample collection, the determination of the physical properties of the lake's surface waters and quantification of phytoplankton biomass. T. Bauersachs analyzed the water column filtrates for their HG content and prepared the manuscript with contributions from all co-authors.

Acknowledgements. The authors thank M. Pohling for assistance during sample collection and extraction of the water column filtrates. Two anonymous reviewers are acknowledged for their constructive comments on the manuscript.

Edited by: H. Niemann

\section{References}

Arp, W., Maier, G, and Michels, U.: Untersuchungen des Phyto- und Zooplanktons schleswig-holsteinischer Seen 2012, Landesamt für Landwirtschaft, Umwelt und ländliche Räume, SchleswigHolstein, Flintbek, 2013.

Bauersachs, T., Compaoré, J., Hopmans, E. C., Stal, L. J., Schouten, S., and Sinninghe Damsté, J. S.: Distribution of heterocyst glycolipids in cyanobacteria, Phytochemistry, 70, 2034-2039, doi:10.1016/j.phytochem.2009.08.014, 2009a. 
Bauersachs, T., Hopmans, E. C., Compaoré, J., Stal, L. J., Schouten, S., and Sinninghe Damsté J. S.: Rapid analysis of long-chain glycolipids in heterocystous cyanobacteria using high-performance liquid chromatography coupled to electrospray ionization tandem mass spectrometry, Rapid Commun. Mass Sp., 23, 13871394, doi:10.1002/rcm.4009, 2009b.

Bauersachs, T., Speelman, E. N., Hopmans, E. C., Reichart, G. J., Schouten, S., and Sinninghe Damsté, J. S.: Fossilized glycolipids reveal past oceanic $\mathrm{N}_{2}$ fixation by heterocystous cyanobacteria, P. Natl. Acad. Sci. USA, 107, 19190-19194, doi:10.1073/pnas.1007526107, 2010.

Bauersachs, T., Compaoré, J., Severin, I., Hopmans, E. C., Schouten, S., Stal, L. J., and Sinninghe Damsté, J. S.: Diazotrophic microbial community of coastal microbial mats of the southern North Sea, Geobiology, 9, 349-359, doi:10.1111/j.1472-4669.2011.00280.x, 2011.

Bauersachs, T., Miller, S. R., van der Meer, M. T. J., Hopmans, E. C., Schouten, S., and Sinninghe Damsté, J. S.: Distribution of long chain heterocyst glycolipids in cultures of the thermophilic cyanobacterium Mastigocladus laminosus and a hot spring microbial mat, Org. Geochem., 56, 19-24, doi:10.1016/j.orggeochem.2012.11.013, 2013.

Bauersachs, T., Stal, L. J., Grego, M., and Schwark, L.: Temperature induced changes in the heterocyst glycolipid composition of $\mathrm{N}_{2}$ fixing heterocystous cyanobacteria, Org. Geochem., 69, 98-105, doi:10.1016/j.orggeochem.2014.02.006, 2014.

Berke, M. A., Johnson, T. C., Werne, J. P., Livingstone, D. A., Grice, K. Schouten, S., and Sinninghe Damsté, J. S.: Characterization of the last deglacial transition in tropical East Africa: Insights from Lake Albert, Palaeogeogr. Palaeocl., 409, 1-8, doi:10.1016/j.palaeo.2014.04.014, 2014.

Brassell, S. C., Eglinton, G., Marlowe, I. T., Pflaumann, U., and Sarnthein, M.: Molecular stratigraphy - A new tool for climatic assessment, Nature, 320, 129-133, doi:10.1038/320129a0, 1986.

Bühring, S. I., Kamp, A., Wörmer, L., Ho, S., and Hinrichs, K. U.: Functional structure of laminated microbial sediments from a supratidal sandy beach of the German Wadden Sea (St. Peter-Ording), J. Sea Res., 85, 463-473, doi:10.1016/j.seares.2013.08.001, 2014.

Castañeda, I. S. and Schouten, S.: A review of molecular organic proxies for examining modern and ancient lacustrine environments, Quaternary Sci. Rev., 30, 2851-2891, doi:10.1016/j.quascirev.2011.07.009, 2011.

De Jonge, C., Stadnitskaia, A., Hopmans, E. C., Cherkashov, G., Fedotov, A., and Sinninghe Damsté, J. S.: In situ produced branched glycerol dialkyl glycerol tetraethers in suspended particulate matter from the Yenisei River, Eastern Siberia, Geochim. Cosmochim. Ac., 125, 476-491, doi:10.1016/j.gca.2013.10.031, 2014.

Gambacorta, A., Trincone, A., Soriente, A., and Sodano, G.: Chemistry of glycolipids from the heterocysts of nitogen-fixing cyanobacteria, Cur. T. Phytochem., 2, 145-150, 1999.

Kangatharalingam, N., Priscu, J. C., and Paerl, H. W.: Heterocyst envelope thickness, heterocyst frequency and nitrogenase activity in Anabaena flos-aqua: influence of exogenous oxygen tension, J. Appl. Microbiol., 138, 2673-2678, 1992.

Larsson, U., Hajdu, S., Walve, J., and Elmgren, R.: Baltic Sea nitrogen fixation estimated from the summer increase in upper mixed layer total nitrogen, Limnol. Oceanogr., 46, 811-820, 2001.
Levine, S. N. and Schindler, D. W.: Influence of nitrogen to phosphorus supply ratios and physicochemical conditions on cyanobacteria and phytoplankton species composition in the Experimental Lakes Area, Canada, Can. J. Fish. Aquat. Sci., 56, 451-466, doi:10.1139/cjfas-56-3-451, 1999.

Nichols, B. W. and Wood, B. J. B.: New glycolipid specific to nitrogen-fixing blue-green algae, Nature, 217, 767-768, doi:10.1038/217767a0, 1968.

Niemann, H., Stadnitskaia, A., Wirth, S. B., Gilli, A., Anselmetti, F. S., Sinninghe Damsté, J. S., Schouten, S., Hopmans, E. C., and Lehmann, M. F.: Bacterial GDGTs in Holocene sediments and catchment soils of a high Alpine lake: application of the MBT/CBT-paleothermometer, Clim. Past, 8, 889-906, doi:10.5194/cp-8-889-2012, 2012.

Powers, L., Werne, J. P., Vanderwoude, A. J., Sinninghe Damsté, J. S., Hopmans, E. C., and Schouten, S.: Applicability and calibration of the $\mathrm{TEX}_{86}$ paleothermometer in lakes, Org. Geochem., 41, 404-413, doi:10.1016/j.orggeochem.2009.11.009, 2010.

Rampen, S. W., Willmott, V., Kim, J. H., Uliana, E., Mollenhauer, G., Schefuss, E., Sinninghe Damsté, J. S., and Schouten, S.: Long chain 1,13-and 1,15-diols as a potential proxy for palaeotemperature reconstruction, Geochim. Cosmochim. Ac., 84, 204-216, doi:10.1016/j.gca.2012.01.024, 2012.

Rethemeyer, J., Schubotz, F., Talbot, H. M., Cooke, M. P., Hinrichs, K. U., and Mollenhauer, G.: Distribution of polar membrane lipids in permafrost soils and sediments of a small high Arctic catchment, Org. Geochem., 41, 1130-1145, doi:10.1016/j.orggeochem.2010.06.004, 2010.

Rodrigo-Gámiz, M., Martinez-Ruis, F., Rampen, S. W., Schouten, S., and Sinninghe Damsté, J. S.: Sea surface temperature variations in the western Mediterranean Sea over the last $20 \mathrm{kyr}$ : a dual-organic proxy $\left(\mathrm{U}_{37}^{K^{\prime}}\right.$ and LDI) approach, Paleoceanography, 29, 87-98, 2014.

Rütters, H., Sass, H., Cypionka, H., and Rullkötter, J.: Phospholipid analysis as a tool to study complex microbial communities in marine sediments, J. Microbiol. Meth., 48, 149-160, doi:10.1016/s0167-7012(01)00319-0, 2002.

Schoon, P. L.: Impact of $\mathrm{CO}_{2}$ and $\mathrm{pH}$ on the distribution and stable carbon isotopic composition of microbial biomarker lipids, $\mathrm{PhD}$ thesis, Utrecht Univeristy, The Netherlands, 2013.

Schouten, S., Hopmans, E. C., Schefuss, E., and Sinninghe Damsté, J. S.: Distributional variations in marine crenarchaeotal membrane lipids: a new tool for reconstructing ancient sea water temperatures?, Earth Planet. Sc. Lett., 204, 265-274, doi:10.1016/s0012-821x(02)00979-2, 2002.

Schouten, S., Hopmans, E. C., and Sinninghe Damsté, J. S.: The organic geochemistry of glycerol dialkyl glycerol tetraether lipids: A review, Org. Geochem., 54, 19-61, 2013.

Smith, M., De Deckker, P., Rogers, J., Brocks, J., Hope, J., Schmidt, S., dos Santos, R. L., and Schouten, S.: Comparison of $\mathrm{U}_{37}^{K^{\prime}}$, $\mathrm{TEX}_{86}^{H}$ and LDI temperature proxies for reconstruction of southeast Australian ocean temperatures, Org. Geochem., 64, 94-104, 2013.

Stal, L. J., Staal, M., and Villbrandt, M.: Nutrient control of cyanobacterial blooms in the Baltic Sea, Aquat. Microb. Ecol., 18, 165-173, doi:10.3354/ame018165, 1999.

Theroux, S., Huang, Y., and Amaral-Zettler, L.: Comparative molecular microbial ecology of the spring haptophyte bloom in 
a Greenland arctic oligosaline lake, Front. Microbiol., 3, 1-10, doi:10.3389/fmicb.2012.00415, 2012.

Thiel, V., Jenisch, A., Landmann, G., Reimer, A., and Michaelis, W.: Unusual distributions of long-chain alkenones and tetrahymanol from the highly alkaline Lake Van, Turkey, Geochim. Cosmochim. Ac., 61, 2053-2064, doi:10.1016/s00167037(97)00038-0, 1997.

Volkman, J. K., Burton, H. R., Everitt, D. A., and Allen, D. I.: Pigment and lipid compositions of algal and bacterial communities in Ace lake, Vestfold Hills, Antarctica, Hydrobiologia, 165, 4157, doi:10.1007/bf00025573, 1998.

Weber, Y., De Jonge, C. Rijpstra, W. I. C., Hopmans, E. C., Stadnitskaia, A., Schubert, C. J., Lehmann, M. F., Sinninghe Damsté, J. S., and Niemann, H.: Identification and carbon isotope composition of a novel branched GDGT isomer in lake sediments: Evidence for lacustrine branched GDGT production, Geochim. Cosmochim. Ac., 154, 118-129, doi:10.1016/j.gca.2015.01.032, 2015.

Weijers, J. W. H., Schouten, S., van den Donker, J. C., Hopmans, E. C., and Sinninghe Damsté, J. S.: Environmental controls on bacterial tetraether membrane lipid distribution in soils, Geochim. Cosmochim. Ac., 71, 703-71, doi:10.1016/j.gca.2006.10.003, 2007.
Whitton, B. A.: Ecology of Cyanobacteria II: Their Diversity in Space and Time, second Edn., Springer, Dordrecht, 2012.

Wolk, C. P.: Heterocysts, in: The Biology of Cyanobacteria, edited by: Carr, N. G. and Whitton, B. A., Blackwell Scientific Publishers, Oxford, UK, 359-386, 1982.

Wörmer, L., Cires, S., Velazquez, D., Quesada, A., and Hinrichs, K. U.: Cyanobacterial heterocyst glycolipids in cultures and environmental samples: diversity and biomarker potential, Limnol. Oceanogr., 57, 1775-1788, doi:10.4319/1o.2012.57.6.1775, 2012.

Zink, K. G., Leythaeuser, D., Melkonian, M., and Schwark, L.: Temperature dependency of long-chain alkenone distributions in recent to fossil limnic sediments and in lake waters, Geochim. Cosmochim. Ac., 65, 253-265, doi:10.1016/s00167037(00)00509-3, 2001.

Zink, K. G., Vandergoes, M. J., Mangelsdorf, K., DieffenbacherKrall, A. C., and Schwark, L.: Application of bacterial glycerol dialkyl glycerol tetraethers (GDGTs) to develop modern and past temperature estimates from New Zealand lakes, Org. Geochem., 41, 1060-1066, doi:10.1016/j.orggeochem.2010.03.004, 2010. 